Desalination, 31(1979) 87-99

c Elsevier Scientific Publishing Company, Amsterdam - Printed in The Netherlands

\title{
A SYSTEM FOR THE EXPERIMENTAL STUOY OF FLASH EVAPORATION
}

NOAM LIOR AND RALPH GREIF

University of Pennsylvania, Philadelphia, Pennsylvania 19l04, and University of California, Berkeley, California 94720

SUMMARY

The performance of meaningful experiments on heat, mass and momentum tra phenomena during flash evaporation in water desalination Multi-Stage Fash requires careful design and construction of the experimental apparatus due very small thermodynamic driving potentials and the generally hostile natur fluid. The paper describes the design philosophy and considerations utiliz construction of a two-stage scaled-down model of a flash evaporator, and tr mentation and techniques developed or adapted for the measurement of temper pressure, flow, level and salinity, and for the visualization of the flow.

\section{INTRODUCTION}

To perform meaningful measurements of heat transfer, mass transfer and $f$ anics phenomena in systems typical to multi-stage flash desalination equipm ful consideration needs to be given to the process characteristics which ha important interaction with the measurement technique and instruments.

The major of these characteristics are the small driving thermodynamics (such as small gradients of temperature, pressure and concentration) implent to economic considerations, and which are hard both to maintain constant ar measure; the mode of evaporation, which includes surface evaporation and bu ation and which is influenced by the placement of measuring probes, by nonc sables and by surfactants; the existence of two phases (vapor and 1iquid) $i$ bulent flow, which complicates measurements significantiy; the heat and nas in the bulk, between the liquid and the many evaporating interfaces, typifi sharp temperature and salt gradients in very thin layers near these interf by rather nonuniform temperature and concentration profiles; the local and dynamics of the process, namely, fluctuations of the same order of magnituc parameter's average magnitude, as well as overall instabilities due to the 
free-surface nature of the-flow which is highly sensitive to condenser temper noncondensables and effect of immersed instruments; transport in the vapor $\mathrm{SF}$ from the flashing liquid to the condenser, which includes convection and diff of vapor and noncondensables and the effect of obstacles on their flow; the $f$ hostile environment composed of brine and distilled water and which is corros scaling and fouling; and the need to sustain both vacuum and pressure in the ting temperature range of MSF units, requiring a well-sealed vessel to preven tration of air and exfiltration of vapor and noncondensables.

The experimental apparatus which was designed and built based on the above $c c$ tions, and which was used successfuliy in extensive experiments (1), is descr below.

GENERAL DESCRIPTION OF THE EXPERIMENTAL EQUIPMENT

The experimental research system consists of a scaled-down model of one st a horizontal flash evaporator with nonflashing inlet stage (Figs. 1, 2). The are channels of rectangular cross section, $78 \mathrm{~mm}$ wide and are separated by ar table sluice gate which forms a full width rectangular flow orifice between The flash stage is connected by means of a full-width-and-length $75^{\circ}$ elbow th length condenser. This arrangement provides a uniform and direct path for th ving vapor so that visual as well as experimental examination of the vapor-1 interface may be carried out.

The whole flash evaporator assembly is mounted on a steel stand which is on a bearing block at one end and can thus be tilted to provide various flowfor the evaporator. The piping connected to the evaporator is flexible in th gion near the fulcrum so that the slope can be readily changed. The flexible in all piping connected to the flash evaporator are also designed to prevent transmission of vibrations which would have interfered with the sensitive mea ments performed in the system.

The flow system (Fig. 3) is a closed loop with an independently cooled cor The flashing liquid is circulated by the main pump and is heated to a constar erature by the verticai, steam-heated heat exchanger. It then enters the int stage and flashes in the flash-stage before returning to the circulation pump flashed-off vapor condenses in the main condenser* and the resulting distilli

*The condenser consists of nine 5/8" 0.D. U-tubes in a shel1 (a11 70-30 copp alloy), $4 \mathrm{ft}$ long. The total heat exchange area is $11 \mathrm{ft}^{2}$. 


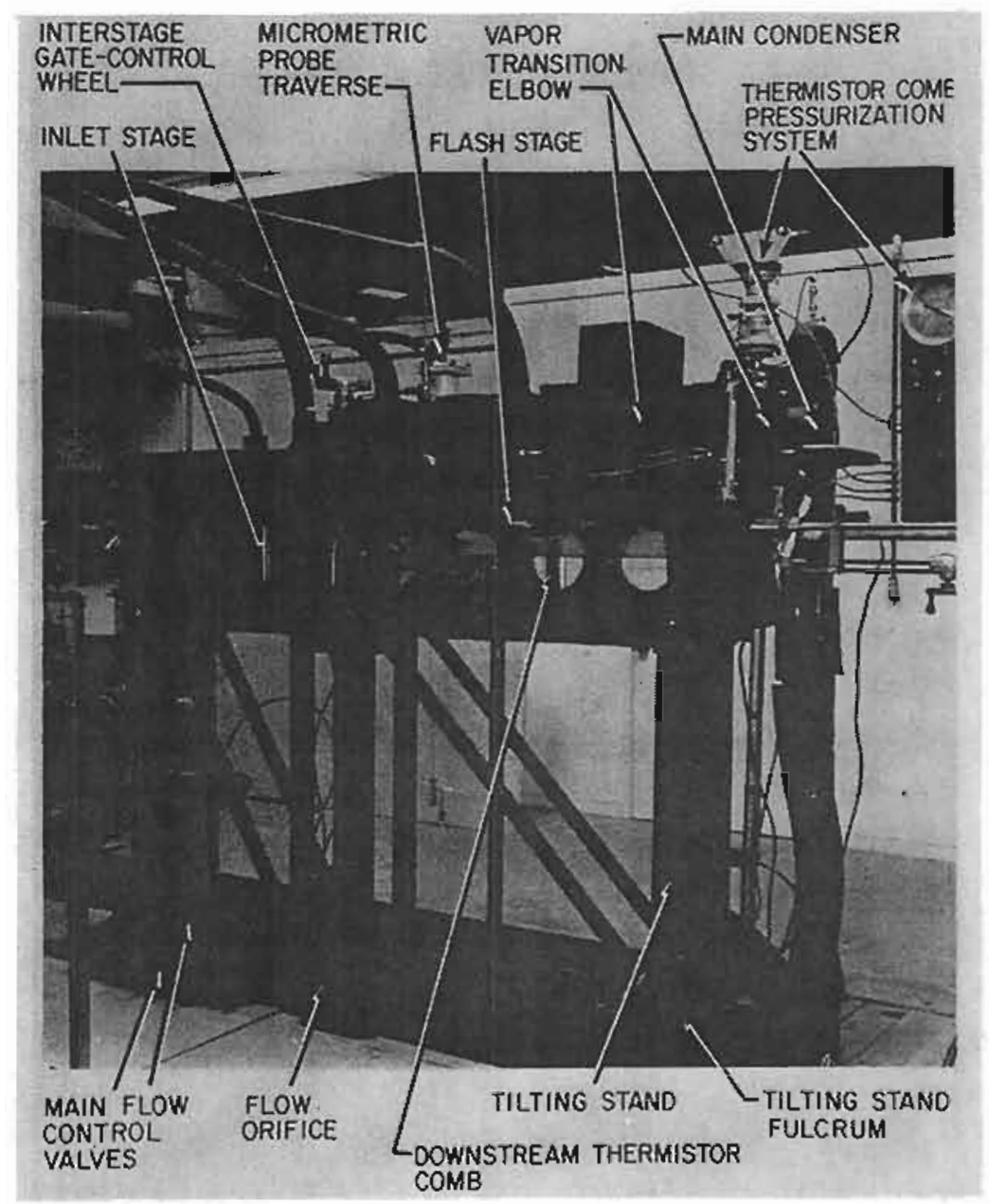

Fig. 1. The flash evaporator

flows by gravity to a distillate collection and measurement system. It is back to the suction side of the main circulation pump. The main condenser by city water, the coolant loop incorporating a cooling tower which is avai when larger quantities of coolant are needed. The whole flow-system is the insulated.

Large and numerous glass windows enable good visual observation of the $p$ In addition, temperatures, pressures, flow rates and salinities are measure' mutiple Tocations throughout the system. These are noted in the flow diag (Fig. 3) and are described below in more detail.

In particular, each evaporator stage is equipped with a wing-shaped sens taining ciosely spaced miniature hypodermic needle thermistor thermometers. some configurational simililarity, these sensors are referred to as "thermi 


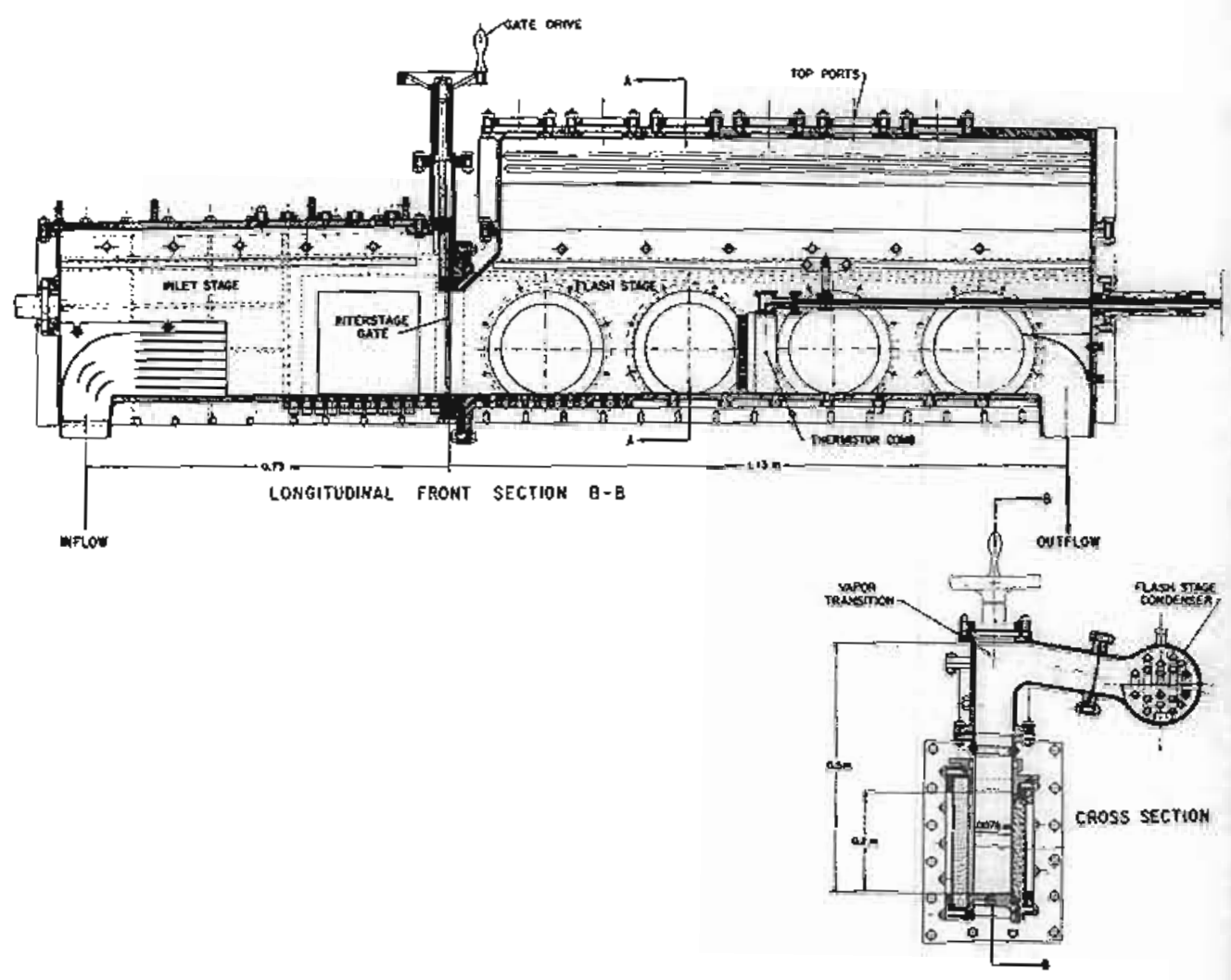

Fig. 2. Cross-sectional views of the flash evaporator

combs". They provide temperature measurements of high accuracy along a 1 ir to the stage floor, in both the liquid and vapor regions. They can be move axial direction along each stage.

Practically all demountable seals in the system are groove-confined $0-R^{\text {: }}$ ethyl ene-propylene elastomer. Ail seals for reciprocal motion (such as in sing instrument probes) are elastomer O-Ring loaded Teflon rings.

The flash evaporator system has been designed to operate from 0 to abou which enables flashing from about ambient temperature to $120^{\circ} \mathrm{C}$. The flow 1 the evaporator can be varied and precisely measured from about 0.063 to 6 . second (1 to $100 \mathrm{gpm}$ ). The system has been designed for operation with fT. liquid levels up to abrut $100 \mathrm{~mm}$, but levels of us to $200 \mathrm{~mm}$ can be accoria The level is changed by adding or withdraw" ng liquid from and to a holding

The vertical heater has sufficient area to supply the heat requir?d for practical flashing rates at all the ilow and temperature conditions aescri Its effective heat transfer area can be varied by adjustment of the conde lavel in the shell. 


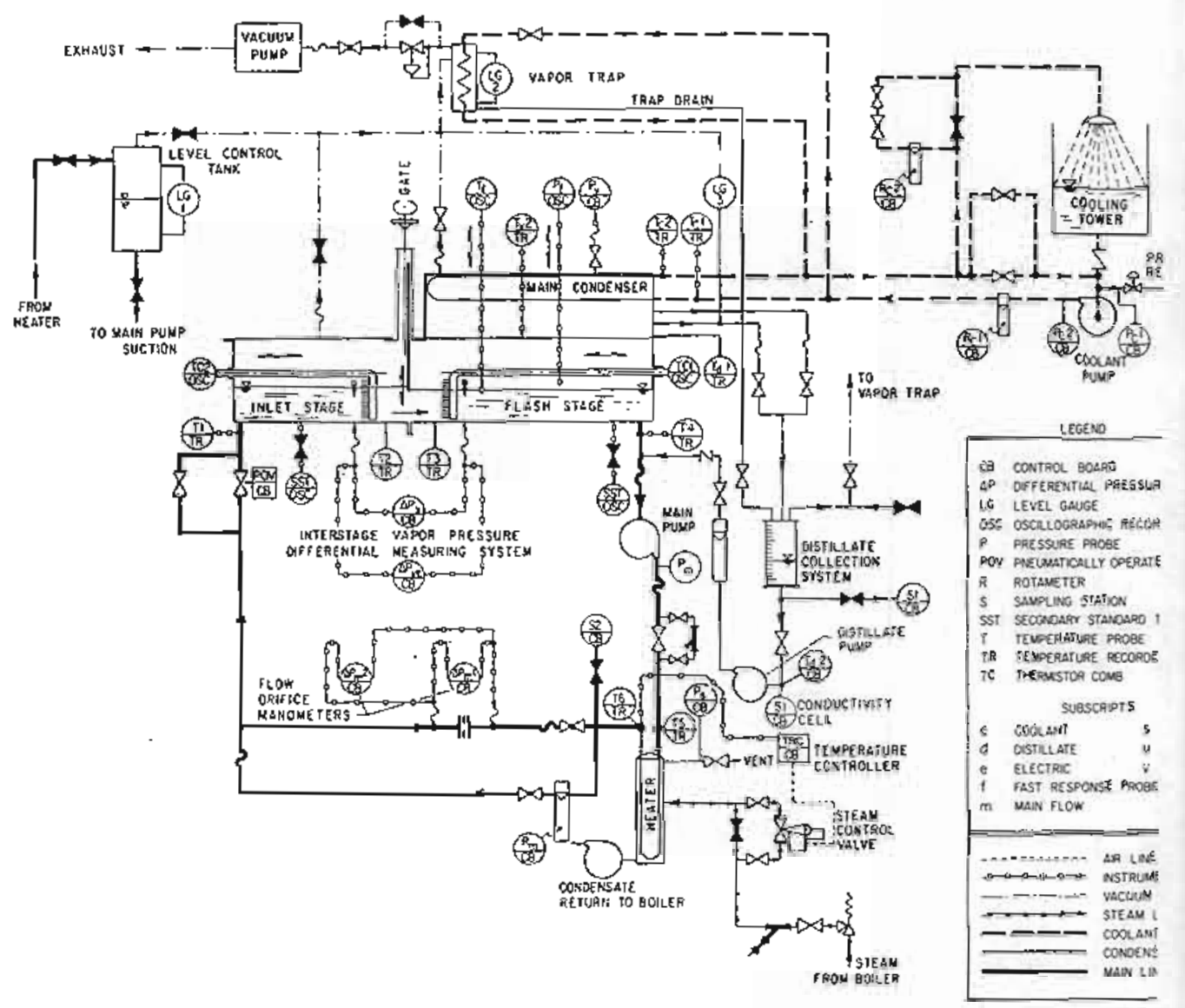

Fig. 3. Flow diagram

Throughout the design and construction, care was taken to make the syste sion resistant so as to avoid contamination of the fluid as wel1 as damage mention.

The controis are essentially concentrated on one board (Fig. 4)) thus en one person to operate and monitor the whole apparatus. Most of the precise tronic measuring components are assembled on a single, wheel mounted cabine

\section{THE FLASH EVAPORATOR}

Both stages and the vapor-transition elbow were cast from 70-30 copper-r alloy. The condenser and most of the piping were fabricated and welded fro same alicy. The castings were arc-weided with a 70-30 copper-nickel rod. castings, particularly in the areas in the vicinity of the welds, were quit and had to be impregnated. Remaining porosity has been locally sealed with 


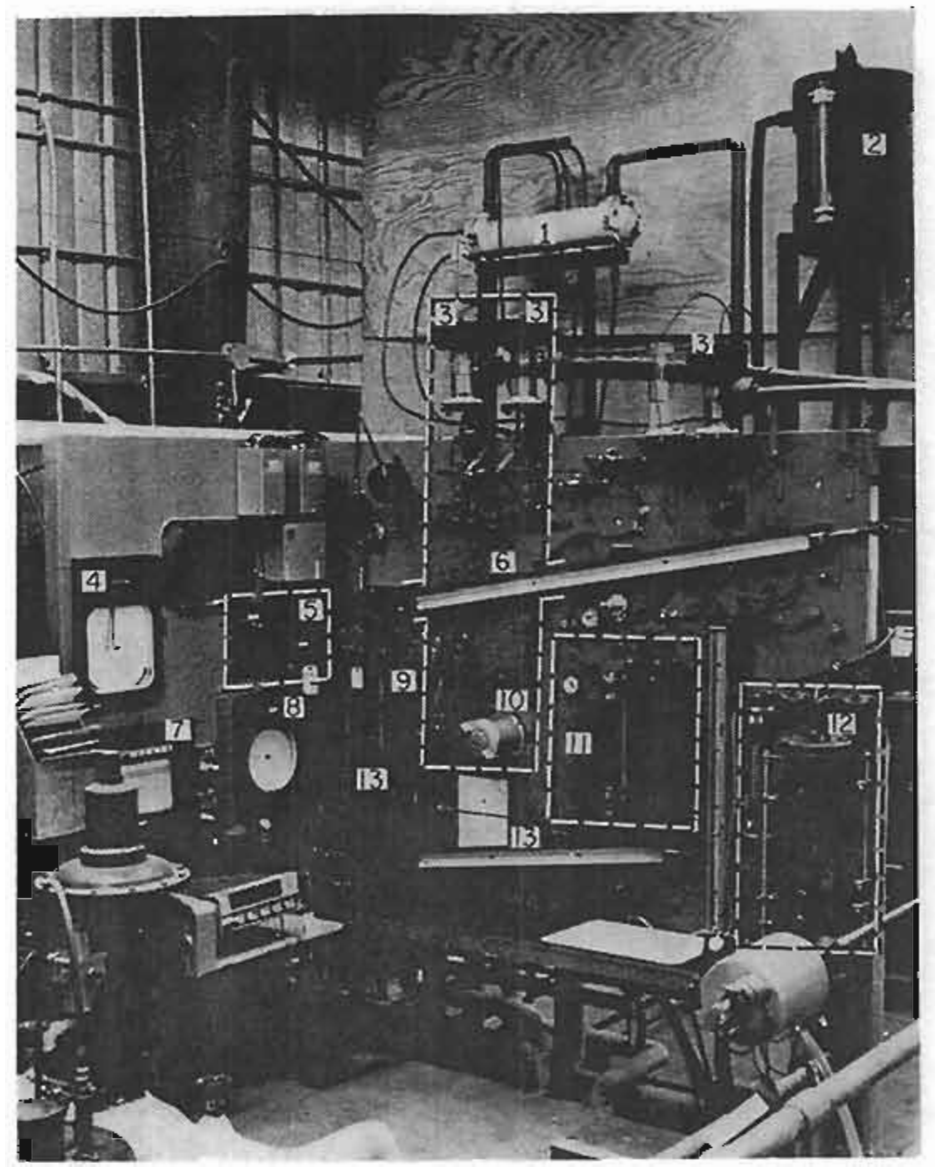

Fig. 4. The control board

(1) vacuuin pump vapor trap (2) holding tank for level control manometer condensate pots (4) temperature controller/recorder (5) condu measurement and alarm (6) interstage vapor $\Delta P$ manometer (7) $\Delta P \& \Delta T$ rec (8) 12 pt. themocouple temperature recorder (9) low range, main flow rot (10) interstage $\triangle P$ electronic transmitter (11) condenser coolant measurem control (12) distillate collection system (13) main flow orifice manome

rubber adhesive/sealants until leaks under full vacuum were reduced to abou per 12 hours for the whole system. Parts fabricated and welded from rolled nickel plates have shown no porosity.

The length of the intet stage is $0.730 \mathrm{~m}$. This was determined to provid combination with flow straightening vanes (at this stage's intet) sufficien uniform flow at the inlet to the flash-stage. The length of the flash stag m. This length is made up of the estimated stage length necessary for flası extreme conditions, and has been determined by Richardsons-Westgarth \& $\mathrm{Co}$. la to be about $0.4 \mathrm{~m}$, plus about 10 hydraulic diameters to reduce the effec stage discharge configuration on the flow in the flashing region. A flow-1 
vane at the stage exit guides the liquid out.

The evaporator was therma $71 y$ insulated and the measured heat loss to the dings (by means of a heat flux meter) never exceeded $3 \%$ of the total evapor heat transfer.

Both stages are equipped with large gias\$* windows on both sides and top. glass in the sides of the stages has been mounted so that the sides form a $c$ surface, without steps (Fig. 2). This has been achieved by having the round windows beveled and by bonding a rectangular glass insert onto the inner sid rectangular windows, thus filling-in the cavity created by the metal frame s the window.

To obtain both adequate themal insulation and conitinous visual access, F plates are mounted at some distance in front of the windows. The circumfere plexiglass plates is pressed against the plastic foam (which insulates the $y$ evaporator) and the resulting sealed air layer provides the necessary therme tion. The plexiglass plates serve also as safety shields for the possibilit dow breakage. None of the windows broke throughout the experiments.

The continuously adjustable gate separating the stages creates a vapor $s$ them by means of an elastomer 0-ring backed Teflon seal along its two sides top. Numerous instrument access ports are available in the flash evaporator and in the process $l$ ine.

PROCESS DESCRIPTION (FIG. 3)

Main $100 \mathrm{p}$

Upon discharge from the main circulation pump, the main liquid stream is byl either partially or fully, through a filter with $5 \mu$ elements, and then entel steam-heated main heat exchanger. The temperature of the liquid at the exi. trolled by an automatic temperature controller which pneumatically operates positioner of the steari control valve. The liquid capacity of the oversized provides the system with satisfactory control dynamics, and the constancy of trolled system temperature had been observed to be within $\pm 0.25^{\circ} \mathrm{C}$ of the se (and usually bettery, this being within the perfomance limits of the contro self. The flow rate is controlled manualy with a parallel combination of remotely operated, valve (POV) and a smaller valve.

Product (distillate) loop

The distillate forming in the main condenser flows by gravity to a colte

*A11 windows were made from-HERCULITE Brand (Pittsburgh Plate Glass Co., On Center, Pittsburgh, PA 15222) tempered plate glass. The rectangular windo 1-1/4" thick, the 4 in. diameter windows at the top are $1 / 2 "$ thick, and the meter windows in one side are $?$ in. thick. 
measurement graduated glass vessel, the vapor space of which is connected vapor space of the condenser. The distillate collection rate is measured vessel with a stop watch. The overall accuracy is $\pm 1 \%$ of the measured flor The vessel is equipped with a sampling system for the distiliate. The conc and the temperature of the distillate are continously measured at the exit vesse1. The level of liquid in the collection vessel is maintained within Timits by a photoelectrically activated controller which turns the distill on and off. For more detail see $(3)$.

\section{The coolant system}

The temperature and flow rate of coolant through the main condenser are factors that determine the vapor pressure in the flash stage, and thereby, of flash-down. This explains the need to control these variables precisel: which has been amply confirmed during the actual experiments.

Due to economic reasons, the control systemwas essentially manual. Cit: piped through a water-pressure regulator to the suction side of the coolan It was then pumped through a rotameter $\left(R_{c} 1\right)$ through the condenser. Most , ant was recirculated by the pump and the rest measured with a rotameter $(R$, either dumped or circulated through a cooling tower from which it was retu system.

The fact that smal1 quanitites of ambient-temperature coolant are mixed larger quantities of hotter, recirculating, coolant provides sensitive con trol. The coolant recirculation loop is thermally insulated. The pump di obtained is constant and so, essentially, is the city water temperature. once the valves are set, both coolant temperature and flow rate attain sta

\section{The vacuum system}

The vacuum system evacuates the noncondensable gases from four vessels: stage, flash stage condenser, level control tank and distillate collection This is performed with a mechanical vacuum pump which maintains, by means regulator, a constant vacuum in the vapor trap installed between it and th The four vessels are connected separately to the vapor trap with needle va vacuum 1 ines are monotonically graded to insure condensate drainage and pr. 1iquid locks. The trap drains the condensate by gravity into the distilla tion vessel, thus insuring that all distillate is measured.

FLOW INSTRUMENTATION

Main flow

Flow rates greater than 0.821 iter/second ( $13 \mathrm{GPM}$ ) are measured with a 
edge ASME (4) flow orifice with an opening dianeter of $32.84 \mathrm{~mm}$, a $\beta_{0}$ rati and Vena contracta taps. The pressure differential across the orifice is with two mercury-filled manometers $\left(\Delta \mathrm{P}_{\mathrm{m}}{ }^{l}\right.$ and $\Delta \mathrm{P}_{\mathrm{m}^{2}}{ }^{2}$ connected in parallel range inclined manometer with divisions of 0.01 " and a 24 " U-tube manomete 0.1 "divisions. This pressure differential measuring system yields an err than $\pm 0.26 \%$ of the mea sured flow.

The orifice has been calibrated in-situ, using city water at ambient te once before and once after the completion of the experiments. No signific rence between the two calibrations has been observed. The calibrated valu compared with those obtained from the ASME formula (4).

Flow rates below 0.82 itter/second are measured by bypassing the flow 1 $0.821 \mathrm{iter} /$ second $\left(13 \mathrm{GPM}\right.$ ) romameter $\left(\mathrm{R}_{\mathrm{m}} 1\right)$. The rotameter has been calibr situ at three temperatures: ambient, $50^{\circ} \mathrm{C}$ and $82^{\circ} \mathrm{C}$ and correction curves tained. The estimated measurement error (after correction) is $\pm 0.25 \%$ of th

Coolant flow

The flow rate of the coolant through the condenser is measured by a 50 meter $\left(R_{c}\right)$. The portion of coolant that is dumped (or circulated througt cooling tower) is measured on a separate, $0.5 \mathrm{gpm}$ rotaneter $\left(T_{c}{ }^{2}\right)$. Both $r$ were calibrated in-situ, obtaining an accuracy of $\pm 0.5 \%$ of the measured ra

PRESSURE

The vapor pressure in the flash stage and the pressure differential bet vapor space of the inlet stage and that of the flash stage are measured at cation taps by manometers. Pressure fluctuations in the liquid or vapor o stage are measured with a piezoelectric pressure gauge* which can be posit several locations along the flow axis and also traversed in the vertical d by means of a micrometer.

There exist many difficulties in measuring vapor pressure with a giassmanometer, including condensation of vapor in the glass tubes, and rapids pressure fluctuations. It was therefore decided to use condensate pots ab manometers (Fig. 4). The pots are automatically replenished by condensati vapor space connected to them. The connection to the vapor spaces is by $m$ copper tubing which is termally insulated. The tubing is monotonically gr the condensate pots down to the measured vapor space, to provide adequate drainage and avoid ijquid locks. The level in the pots is therefore self when the condensate level rises about the vapor inlet, it drains back into

*F.S. Range: $10 \mathrm{psia}$; Sensitivity: $100 \mathrm{mV} / \mathrm{psi}$; Model 201Ai, Kistler Instr Co., Overlake Industrial Park, Redmond, WA 98052. 
respective evaporator stage..

The interstage vapor pressure differential was measured simuitaneously by instruments connected in parallel: a 250 mon inclined mercury-in-giass manom $0.01 "(0.25 \mathrm{~mm})$ divisions and an electronic djfferentia 1 pressure transmitte an adjustable full-scale range of $37 \mathrm{~mm} \mathrm{Hg}$ to $370 \mathrm{~mm} \mathrm{Kg}$. The electronic tri output is recorded on a potentiometric recorder, after appropriate signal cs ing. The transmitter has been calibrated by comparing its output signal to pressure measured simultaneously on the inclined manometer. The estimated $;$ of both systerns is $\pm 0.13 \mathrm{~min} \mathrm{Hg}$

\section{TEMPERATURE MEASUREMENT}

To experimentaliy obtain accurate temperature-profiles in the flash evap several complementing temperature measuring systems have been designed and The "thermistor comb", that is, a vertical sensor incorporating closely spa ture thermistors, enables a simultaneous measurement of absolute and differ temperatures in the liquid and vapor phases along a line perpendicular to $t$ floor. This method provides the necessary accuracy in the measurement of $t$ temperature differentials associated with flash evaporation, provides direc thermal driving force for evaporation (from the measured temperature oiffer tween the 1 iquid and the vapor) and determines the temperature gradients in phases and across the phase interface, which are indicative of the rate of port. In addition, the influence of the sensor on the measured medium is $f$ contrast to the more commonly used vertically traversing probe which may ir extraneous effects at different positions. One such sensor is located in $t$ stage and one in the inlet stage. Thermistors were chosen to measure tempe mainly because of their high temperature sensitivity and their availability small size.

The basic measuring element is a $0.070^{\prime \prime}(0.25 \mathrm{~mm})$ diameter bead thermist lated in glass**. Its nominal resistance at $25^{\circ} \mathrm{C}$ is 100,000 ohm, and it is the end of a $0.46 \mathrm{~mm}$ diameter type 304 stainless steel hypodermic tube, whi serves as the conduit for the two thermistor wires. Sixty-eight such thern probes are present in the flash-stage comb, thirty-six in the inlet-stage They are mounted into a streamlined, wing-shaped holder whose disassembled part is shown in Fig. 5 .

*F.S. Range: adjustabie from 0-20 to 0-200 inch water; Model 1082491EK, F Porter Co., Warminster, PA 18974.

**Part No. G51A59, Victory Engineering Corp., Spring Ave, Springfield, NJ o 


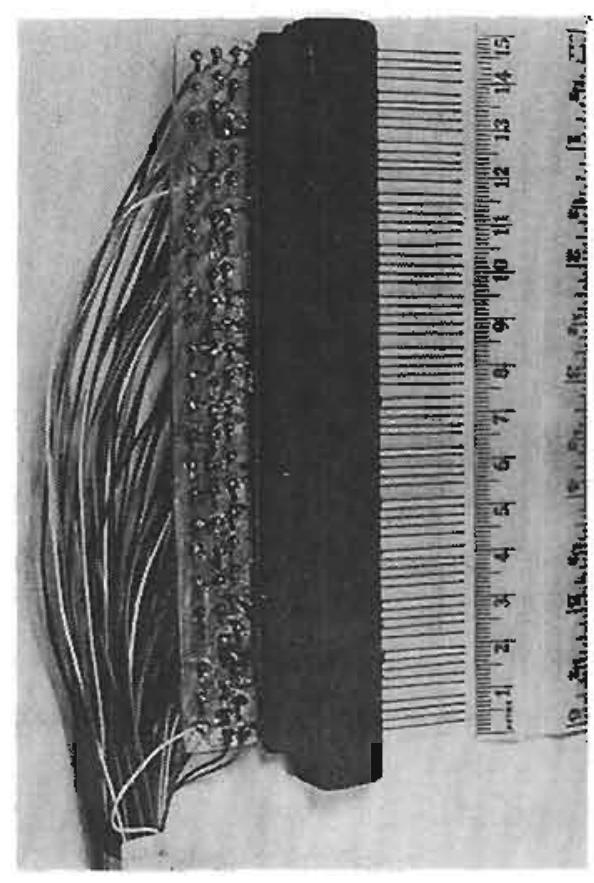

Fig. 5. Front part (disassembied) of the thermistor comb

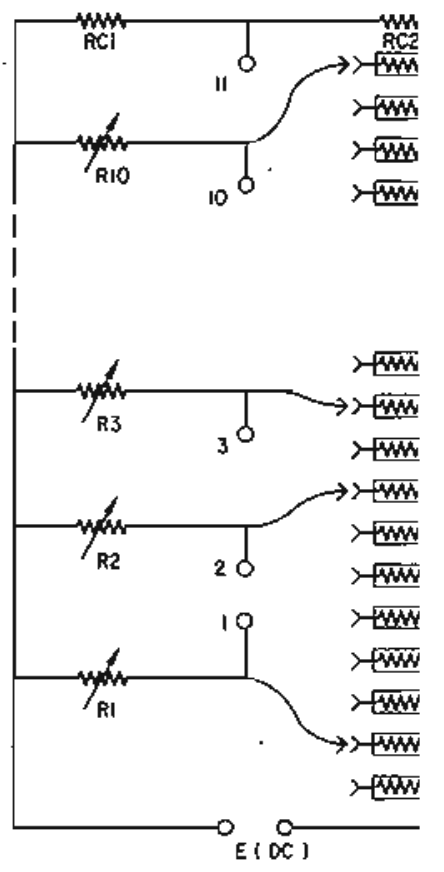

Fig. 6. Differential 8ridge with "absolute" ref

Two miniature thermistors were mounted in the end of $1 / 8$ in. 0.0 . stainl tubes and served as secondary temperature standards (SST) for the calibrat the thermistor combs as well as providing temperature measurements in both stages.

The resistance of the thermistors was determined by ten $\mathrm{OC}$ Wheatstone $\mathrm{Br}$ output of each bridge was amplified, conditioned and recorded on a 12-chan lographic recorder and thus, the temperatures of any ten thermistors could simultaneously. Each bridge could be connected to any thermistor by means cord system. Essentially, the resistance measuring circuit consisted of o ence and nine differential bridges (Fig. 6). Any one of the thermistors $i$ system could be chosen as the reference.

A11 bridge components, as well as all other components in the electronic were selected for their stability and accuracy, and were assembled into a stabilized $\left( \pm 1^{\circ} \mathrm{C}\right)$ cabinet, so as to achieve a resistance measurement of th $0.01 \%$ of the measured value.

The thermistor combs were calibrated in-situ, by their total immersion i temperature, nonflashing water circulating through the flash evaporator. dary standard thermistor probes, one for each stage, were traversed vertic. 
upstream of the comb and served as the temperature reference. In the calibri procedure, this reference probe was placed upstream of each thermistor in th and was always connected to the reference bridge. The comb thermistor being brated was connected to the adjacent differential bridge, the output signals bridges were balanced on the oscillograph, and the values of the balancing re $R 1$ and $R 2$ of each of the two bridges (Fig. 6) were recorded. The value of $R$ mined the local calibration temperature (by the below-described calculation) while $R 2$ is the resistance of the calibrated thermistor at that temperature.

The secondary standard thermistor references were, in turn, calibrated in bath maintained at constant $\left( \pm 0.07^{\circ} \mathrm{C}\right)$ temperature by means of a temperaturecirculation bath. The temperature reference was a platinum standard thermom measured on a Mueller Bridge with a high-sensitivity mirror-galvanometer.

To translate the bridge measurements to temperature, the relationship bet: the resistance of the thermistors and their temperature (the R-T curve) was mined during calibration. From the R-T curve and the circuit equations, a $r$ was derived between the reference and differential temperatures of the thern and the actually recorded values of resistance and oscillographic galvanome1 flection. These relations were programmed for a digital computer to yield i priate reference and differential-temperature distributions both in tabular graphical form. The overall accuracy of the Thermistor comb system for mea: temperatures was $\pm 0.02^{\circ} \mathrm{C}$. Other details on the Thermistor Comb and its mea: circuits are descirbed in (5).

In addition to the thermistors, twelve thermocouples at fixed locations o entire flow loops were used mainly for process monitoring. Also, a $5 \mu$ s res, film platinum resistance thermometer $\left(T_{f}\right)$ was mounted on a micrometric vert traverse orive. This was used to measure temperature profiles across the ting 1 iquid-vapor interface, and could detect high-frequency temperature $f 1$

\section{PHOTOGRAPHY}

Still photographs of the flashing process were taken during each experime and a 16 mim mavie was taken during one run. Most of the still pictures wer on Polaroid film with a Speed-Graphic camera. Photography of the process $i$ difficult by the reflections coming from the glass windows and by the turbu phase fluid. Reasonably good results were obtained by using polarizing fil mounted on both the camera lens and the light source (an electronic flash to the subject by a silver-colored reflection screen). The flash duration about 1 millisecond, except for some pictures that were taken with an ultro lous strobe. The filters and the lighting technique has eliminated most of while the fast speed of the flash helped reduce the blur emating from the $\pi$ the fluid. 


\section{ACKNOWLEDGEMENT}

The authors wish to ackiowledge the invaluable assistance to this study by Messrs. 3. C. Hensley, G. P. Schwab, P. G. Young, and Dr. J. Leibovitz, support and counsel extended by Dr. A. D. K. Lajrd. The work was funded b Seawater Conversion Laboratory of the University of California, Berkeley.

\section{REFERENCES}

1. N. LIOR ANO R. GREIF, Proc. 5th Int'1. Symp. on Fresh water from the Se Conte, Sardinia, Ita yy, May 1976.

2. RICHARDSONS WESTGARTH \& CO., LTD., U.S.D.I., O.S.W., R \& D ProgresS ReF 1964.

3. N. LIOR, J. LEIBOVITZ AND A.D.K. LAIRO, Desalination, I3 (1973) 91.

4. AMERICAN SOCIETY OF MECHANICAL ENGINEERS, Fluid Meters, Their Theory al tion, 5th Ed., ASME, NY, NY (1959).

5. N. LIOR, J. LEIBOVITZ AND A.D.K. LAIRD, Rev. Sci. Instr., 45 (1974) 13. 
$$
-
$$ 